\title{
APLIKASI FORECASTING KEHADIRAN SISWA DI SMP 2 JEKULO MENGGUNAKAN METODE REGRESI LINEAR
}

\author{
Peni Retnowati \\ Fakultas Teknik, Program Studi Teknik Informatika \\ Universitas Muria Kudus \\ Email: 201751218@std.umk.ac.id \\ Tutik Khotimah \\ Fakultas Teknik, Program Studi Teknik Informatika \\ Universitas Muria Kudus \\ Email: tutik.khotimah@umk.ac.id
}

\begin{abstract}
ABSTRAK
Kehadiran siswa memegang peranan penting dalam kegiatan belajar mengajar. Keterlibatan siswa dalam kegiatan belajar mengajar secara langsung akan menimbulkan interaksi belajar mengajar berjalan dengan baik, memudahkan terjadinya transfer ilmu pengetahuan secara langsung dari guru ke siswa. Siswa yang hadir memungkinkan untuk lebih aktif dalam interaksi belajar mengajar, berbeda dengan siswa yang tidak hadir, hal ini akan berimplikasi pada prestasi belajar siswa. Kehadiran siswa juga berpengaruh pada kelancaran siswa dalam melanjutkan ke jenjang kelas selanjutnya, karena untuk bisa naik kelas maka siswa harus memenuhi prosentase kehadiran yang ditetapkan oleh sekolah termasuk oleh SMP 2 Jekulo. SMP 2 Jekulo menetapkan siswa dapat naik kelas jika memenuhi kehadiran 85\%. Dimana siswa tidak dapat naik kelas jika terdapat Alpha (tidak hadir tanpa keterangan) lebih dari 14. Ketidakhadiran siswa terdiri dari tiga kategori yaitu sakit, izin dan alpha. Tujuan penelitian adalah untuk membuat aplikasi forecasting yang dapat digunakan untuk memprediksi ketidakhadiran siswa yaitu dengan kategori sakit, izin dan alpha. Metode analisis prediksi ketidakhadiran siswa menggunakan metode analisis regresi linear sederhana. Tahapan penelitian yakni pengumpulan data, analisis kebutuhan sistem, perancangan sistem dan implementasi. Aplikasi forecasting kehadiran siswa ini berbasis web, dibuat dengan menggunakan bahasa pemrograman PHP. Hasil penelitian adalah dibangun aplikasi yang dapat digunakan untuk memprediksi keketidakhadiran siswa pada bulan tertentu menggunakan data pada periode sebelumnya.
\end{abstract}

Kata kunci: forecasting, web, analisis regresi linear sederhana, kehadiran siswa

\begin{abstract}
The presence of students plays an important role in teaching and learning activities. The involvement of students in teaching and learning activities directly will lead to interaction of teaching and learning going well, facilitating the transfer of knowledge directly from teacher to student. Students who attend make it possible to be more active in teaching and learning interactions, in contrast to students who are absent, this will have implications for student achievement. The presence of students also affects the smoothness of students in continuing to the next level of class, because to be able to move up the class, students must meet the percentage of attendance set by the school, including by SMP 2 Jekulo. Junior High School 2 Jekulo determined that students could move up if they meet $85 \%$ attendance. Where students cannot graduate if there is an Alpha (absent without information) more than 14. Student absence consists of three categories, namely illness, permission and alpha. The purpose of this study is to create a forecasting application that can be used to predict student absence from the sick, permission and alpha categories. The prediction analysis method for student absence uses the simple linear regression analysis method. The stages of research are data collection, system requirements analysis, system design and implementation. This student attendance forecasting application is web based, created using the PHP programming language. The results of the study are built applications that can be used to predict the absence of students in a particular month using data in the previous period.
\end{abstract}


Keywords: forecasting, web, simple linear regression, student attendance

\section{PENDAHULUAN}

Belajar adalah suatu aktivitas atau suatu proses untuk memperoleh pengetahuan, meningkatkan keterampilan, memperbaiki perilaku, sikap dan mengkokohkan kepribadian. Berkaitan dengan hal tersebut, kegiatan belajar siswa tidak akan berjalan dengan baik, apabila siswa tidak meluangkan dan membagi waktunya untuk belajar dengan sebaik-baiknya. Melihat hal ini, pemanfaatan waktu yang baik oleh siswa untuk belajar akan menimbulkan kesadaran terhadap pentingnya keterlibatan siswa secara aktif hadir dalam kegiatan belajar mengajar sehingga memungkinkan terjadinya interaksi belajar mengajar dengan baik [1].

Kondisi di lapangan guru atau sekolah dihadapkan pada permasalahan bahwa siswa seringkali dengan mudah meninggalkan kegiatan belajar mengajar dengan alasan izin atau tanpa izin. Hal yang sama terjadi di SMP 2 Jekulo, dimana masih banyak siswa - siswa di SMP 2 Jekulo yang tidak masuk sekolah tanpa keterangan ketidakhadiran secara jelas. Siswa yang sering tidak mengikuti kegiatan pembelajaran akan berdampak buruk tertinggal pelajaran dengan siswa yang lain. Dan jika jumlah ketidakhadiran melewati batas yang ditetapkan maka sebagai konsekuensinya menjadi salah satu pertimbangan untuk siswa yang bersangkutan tidak naik kelas.

Mengingat pentingya kehadiran siswa dalam kegiatan belajar mengajar, maka sekolah perlu mengadakan langkah antisipatif agar ketidakhadiran siswa dapat diminimalisir. Langkah antisipatif meminimalisir ketidakhadiran siswa akan lebih akurat jika sekolah mempunyai dasar pertimbangan dengan melakukan forecasting atau peramalan ketidak hadiran siswa dalam waktu tertentu, dengan kategori ketidak hadiran yaitu sakit, izin dan alpha.

Ada banyak metode yang terdapat dalam forecasting, salah satunya metode regresi linear sederhana. forecasting dan perhitungan metode regresi linear telah diterapkan dalam penelitian diberbagai bidang. Metode Regresi Linear sangat membantu dalam perhitungan peramalan pembukaan kelas, dimana metode ini sangat mudah dan sederhana dalam mengimplementasikan kedalam sistem [2]. Metode regresi linear juga diterapkan dalam memprediksi jumlah penjualan Batik Lasem pada KUB Sarwo Endah [3]. Penggunaan metode regresi linear selanjutnya digunakan untuk memprediksi anggaran penjualan [4], hasil penelitian menyatakan anggaran penjualan yang disusun PD. Idaman melalui peramalan penjualan secara kualitatif dalam upaya meningkatkan penjualan perusahaan berjalan cukup baik, Hasil analisis efektivitas menemukan bahwa target penjualan yang disusun dalam anggaran penjualan PD. Idaman selama tahun 2012-2016 cukup efektif karena selisih antara target dan hasil penjualan sudah cukup optimal. Metode Linier Regresi juga digunakan untuk memprediksi mahasiswa registrasi secara tepat [5] serta diterapkan pada prediksi penjualan properti berdasarkan data penjualan properti pada PT XYZ [6].

Penelitian tersebut memiliki persamaan dengan penulis, yaitu mengenai konsep dan metode prediksi yaitu sama-sama melakukan peramalan atau forecasting dengan menggunakan metode regresi linear. Sejalan dengan penelitian-penelitian sebelumnya tersebut, penulis tertarik untuk membangun aplikasi yang dapat memudahkan dalam prediksi ketidakhadiran siswa dengan kategori sakit, izin dan alpha. Aplikasi dibangun menggunakan pemrograman PHP.

\section{METODOLOGI PENELITIAN}

\subsection{Tinjauan Pustaka}

\section{a. Kehadiran Siswa dalam Proses Belajar Mengajar}

Pengertian kehadiran di sekolah bukan hanya berarti peserta didik secara fisik ada di sekolah, melainkan ialah keterlibatan siswa dalam kegiatan-kegiatan sekolah, seperti di sebutkan dalam "dictionary of education", good carter: "attendance at school not merely being bodily presence but incluiding actual participation in the work and activities of the school" [7].

Dari definisi di atas, dapat disimpulkan bahwa kehadiran peserta didik ialah keikutsertaan peserta didik secara fisik dan mental, serta keterlibatan mereka dalam kegiatan-kegiatan sekolah. Sedangkan ketidakhadiran peserta didik bisa di kata, tidak terlibatnya peserta didik dalam kegiatan sekolah.

Pada umumnya ketidakhadiran siswa dapat dibagi kedalam tiga bagian: 
a) Alpa, yaitu ketidakhadiran tanpa keterangan yang jelas, dengan alasan yang tidak bisa dipertanggungjawabkan;

b) Izin, ketidakhadiran dengan keterangan dan alasan tertentu yang bisa dipertanggungjawabkan, biasanya disertai surat pemberitahuan dari orang tua;

c) Sakit, ketidakhadiran dengan alasan gangguan kesehatan, biasanya disertai surat pemberitahuan dari orang tua atau surat keterangan sakit dari dokter.

\section{b. Forecasting}

Forecasting merupakan teknik untuk menduga, memperkirakan suatu kondisi di masa yang akan datang berdasarkan pada kondisi masa lalu dan sekarang, sehingga dapat dengan tepat memperkirakan suatu tindakan atau keputusan. Fungsi dari forecasting ini dapat dikatakan sebagai tindakan dasar pada saat seseorang melakukan tahap perencanaan, misalnya anggaran, jumlah penjualan, perencanaan produksi dan persediaan, sumber daya misalnya jumlah tenaga kerja, serta perencaan kebutuhan bahan baku.

Dua hal pokok yang harus diperhatikan dalam proses forecasting atau peramalan yang akurat dan bermanfaat adalah pengumpulan data yang relevan berupa informasi yang dapat menghasilkan peramalan yang akurat dan pemilihan teknik peramalan yang tepat yang akan memanfaatkan informasi data yang diperoleh semaksimal mungkin [8].

Dengan melakukan peramalan, para perencana dan pengambil keputusan akan dapat mempertimbangkan alternatif-alternatif strategi yang lebih luas daripada tanpa peramalan. Dengan demikian berbagai rencana strategi dan aksi dapat dikembangkan untuk menghadapi berbagai kemungkinan yang bisa terjadi di masa mendatang.

Terdapat tiga jenis metode peralaman, yaitu metode time series, metode regresi, dan metode kualitatif :

a) Metode Time Series merupakan salah satu teknik statistik yang menggunakan data permintaan historis untuk memprediksi masa depan permintaan.

b) Metode Regresi, yaitu sebuah metode statistik juga yang melakukan peramalan dengan menggunakan pengembangan hubungan matematis antara variable yaitu variable dependen (Y) dengan variable Independen $(\mathrm{X})$. Dalam metode regresi suatu model perlu dispesifikasikan sebelum dilakukan pengumpulan data.

c) Metode Kualitatif, merupakan sebuah metode yang digunakan untuk memutuskan hal-hal yang berhubungan dengan proses perencanan yang panjang dengan menggunakan penilaian manajemen, keahlian, dan pendapat sehingga dapat dihasilkan suatu perkiraan.

\section{c. Metode Regresi Linear}

Metode Analisa Regresi Linear Sederhana adalah Metode Statistik yang berfungsi untuk menguji sejauh mana hubungan sebab akibat antara Variabel Faktor Penyebab (X) terhadap Variabel Akibatnya. Faktor Penyebab pada umumnya dilambangkan dengan $\mathrm{X}$ atau disebut juga dengan Predictor sedangkan Variabel Akibat dilambangkan dengan Y atau disebut juga dengan Response. Regresi Linear Sederhana atau sering disingkat dengan SLR (Simple Linear Regression) juga merupakan salah satu Metode Statistik yang dipergunakan dalam melakukan peramalan ataupun prediksi .

Secara matematis model analisis regresi linier sederhana dapat digambarkan sebagai berikut:

$$
\beta_{1}=\frac{\sum_{i=1}^{n} Y_{i} X_{i}-\frac{\left(\sum_{i=1}^{n} Y_{i}\right)\left(\sum_{i=1}^{n} X_{i}\right)}{n}}{\sum_{i=1}^{n} X_{i}^{2}-\frac{\left(\sum_{i=1}^{n} X_{i}\right)^{2}}{n}}
$$

$$
\boldsymbol{\beta}_{\mathbf{0}}=\bar{\gamma}-\boldsymbol{\beta}_{\mathbf{1}} \bar{x}
$$

$$
\gamma=\beta_{0}+\beta_{1} \times
$$

Keterangan: 
$\mathrm{Y}=$ variabel terpengaruh

$\beta_{0=}$ konstanta

$\beta_{1}=$ gradien garis

$\mathrm{X}=$ variable pemberi pengaruh

Secara praktis analisis regresi linier sederhana memiliki kegunaan sebagai berikut:

a) Model regresi sederhana dapat digunakan untuk forecasting atau memprediksi nilai Y. Namun sebelum melakukan forecasting, terlebih dahulu harus dibuat model atau persamaan regresi linier. Ketika model yang fit sudah terbentuk maka model tersebut memiliki kemampuan untuk memprediksi nilai $\mathrm{Y}$ berdasarkan variabel Y yang diketahui.

b) Mengukur pengaruh variabel $\mathrm{X}$ terhadap variabel $\mathrm{Y}$. Hubungan antara variabel dalam analisis regresi bersifat kausalitas atau sebab akibat.

\subsection{Kerangka Pemikiran}

Kerangka pemikiran penelitian dapat dilihat pada gambar 1.

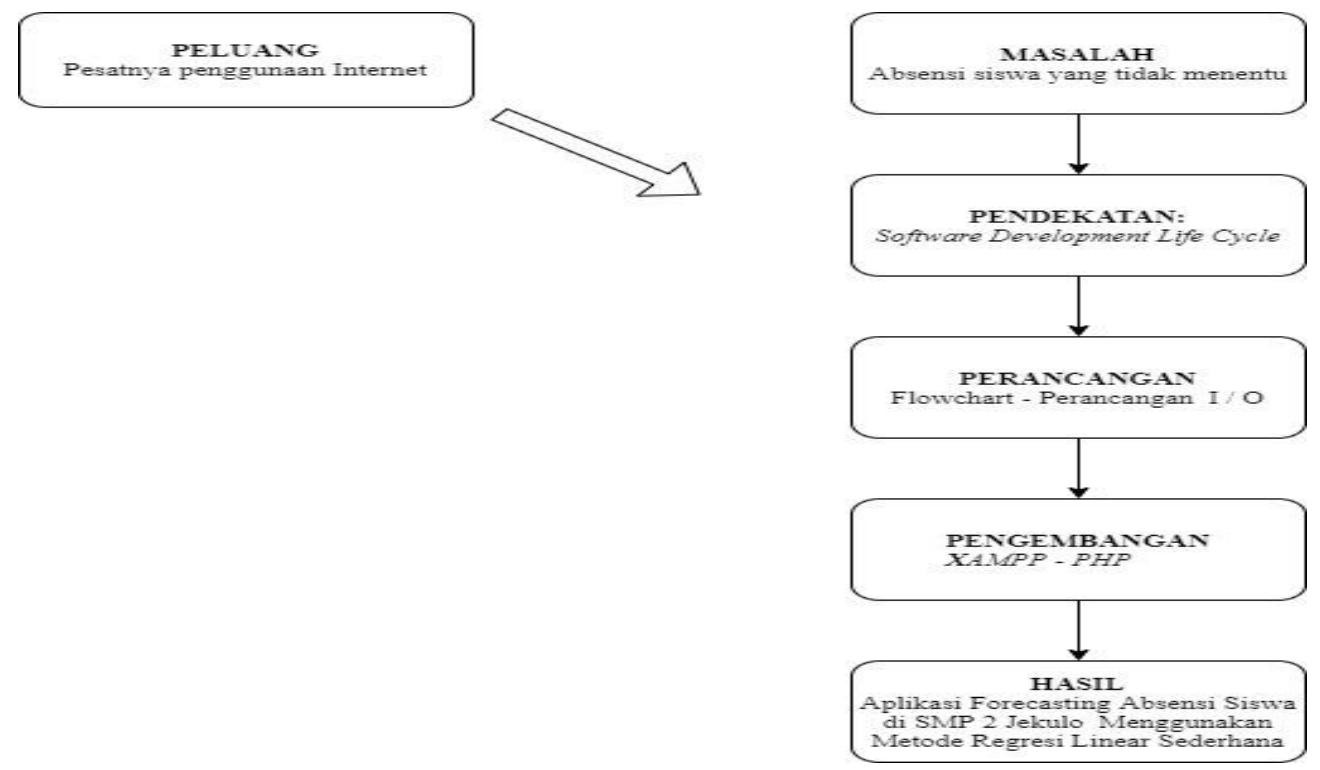

\subsection{Metode Penelitian}

Gambar 1. Kerangka Pemikiran

Penelitian ini adalah penelitian rekayasa perangkat lunak (research and development). Metode yang digunakan adalah Software Development Life Cycle (SDLC). Tahapan penelitian sebagai berikut:

a. Pengumpulan Data

Pada tahap ini dilakukan pengumpulan data berupa rekapitulasi absensi siswa SMP 2 Jekulo pada semester 1 Tahun Pelajaran 2019 / 2020 dengan kategori ketidak hadiran yaitu sakit, izin dann alpha.

b. Analisa

Setelah dilakukan pengumpulan data, tahap berikutnya adalah melakukan analisa kebutuhan sistem.

c. Perancangan

Pada tahap ini dilakukan perancangan sistem dengan menggunakan Entity Relationship Diagram, Data Flow Diagram dan flowchart. Selain itu juga dilakukan perancangan antarmuka (input/output). 
d. Implementasi

Tahap implementasi adalah tahap pengkodean terhadap rancangan-rancangan yang telah dirancang dan didefinisikan sehingga akan membentuk sistem yang diharapkan. Pengkodean sistem dilakukan dengan menggunakan bahasa pemprograman PHP. Pada sistem ini, MySQL digunakan sebagai basis data. Rancangan basis data juga diimplementasikan menjadi sebuah basis data yang dapat digunakan untuk menyimpan data sesuai kebutuhan. Aplikasi dibangun dengan software XAMPP versi 5.6.33, PHP 4.9.4, Google Chrome 72.0 dan Notepad ++. Pada tahap implementasi, dilakukan penyusunan View dan Logic sesuai perancangan yang telah dibuat.

\section{HASIL DAN PEMBAHASAN}

\subsection{Analisis}

\section{a. Entity Relationship Diagram}

Pada perancangan sistem yang dibuat agar dapat menjadi sistem database yang rapi dan terstruktur, maka membutuhkan Entity Relationship Diagram (ERD), yaitu tools yang digunakan untuk melakukan pemodelan data secara abstrak dengan tujuan untuk mendeskripsikan atau menggambarkan struktur dari data yang digunakan [9]. Entity Relationship Diagram (ERD) juga model untuk menyusun database agar dapat menggambarkan data yang mempunyai relasi dengan database yang akan dirancang seperti yang ditunjukkan pada Gambar 2

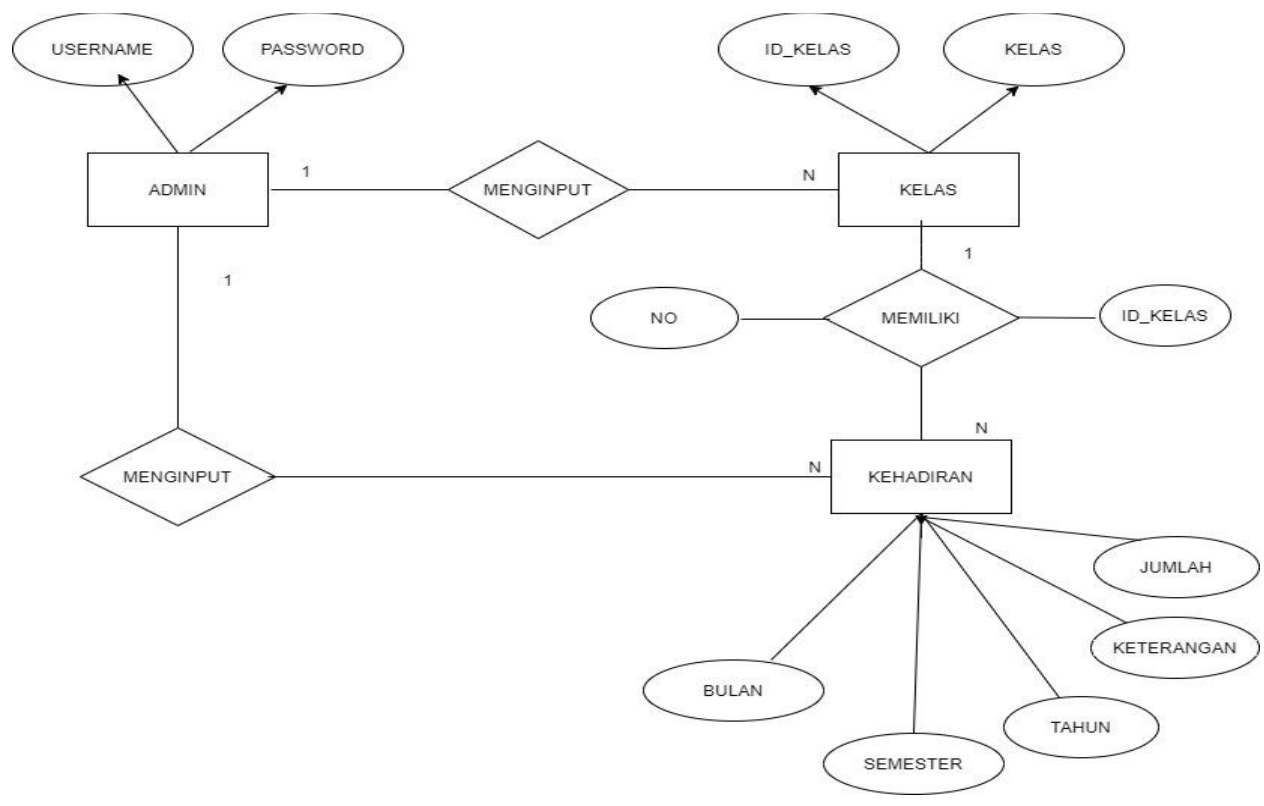

Gambar 2. Entity Relation Diagram

\section{b. Pembuatan Tabel Data}

Pada tahap ini, dibuat tabel data yang nantinya akan dimasukkan ke dalam basis data. Adapun tabel data tersebut antara lain sebagai berikut:

\section{Tabel Kehadiran}

Terdiri dari berbagai macam data yang ditulis untuk membuat data forecasting. Mulai dari data kelas, bulan, semester, tahun, keterangan (S/I/A) dan jumlah dari (S///A), ditunjukkan pada Tabel 3.

Tabel 3. Tabel Kehadiran 


\begin{tabular}{cccc}
\hline No & Field & Tipe Data & Panjang \\
\hline 1 & No & Int & 4 \\
2 & Id_Kelas & Int & 2 \\
3 & Bulan & Int & 2 \\
4 & Semester & Varchar & 6 \\
5 & Tahun & Int & 4 \\
6 & Keterangan & Varchar & 1 \\
7 & Jumlah & Int & 3 \\
\hline
\end{tabular}

2. Tabel Kelas

Berisi identitas kelas yang akan dilakukan prediksi kehadiran, ditunjukkan pada Tabel 4.

Tabel 4. Tabel Kelas

\begin{tabular}{cccc}
\hline No & Field & Tipe Data & Panjang \\
\hline 1 & Id Kelas & Int & 2 \\
2 & Kelas & Varchar & 10 \\
\hline
\end{tabular}

\section{Tabel Admin}

Berisi identitas pengguna (admin) yang dapat mengakses aplikasi. Username dan Password diperlukan untuk masuk ke dalam sistem. Ditunjukan pada tabel 5

Tabel 5. Tabel Admin

\begin{tabular}{cccc}
\hline No & Field & Tipe Data & Panjang \\
\hline 1 & User Nama & Varchar & 25 \\
2 & Password & Varchar & 25 \\
\hline
\end{tabular}

\section{c. Data Flow Diagram}

Setelah relasi dari basis data (ERD) dan tabel data telah dibuat, selanjutnya adalah membuat Data flow diagram (DFD) . Data Flow Diagram adalah representasi grafik yang menggambarkan aliran informasi dan transformasi yang diaplikasikan sebagai data yang mengalir dari masukan dan keluaran [10]. Dengan demikian Data flow diagram (DFD) untuk menggambarkan proses alur aplikasi yang dipadukan dengan data yang telah ada sehingga dapat berinteraksi antara data dengan alur programnya.

Dalam DFD Level 0, menjelaskan alur Admin akan melakukan proses login pada aplikasi, jika proses login berhasil maka sistem akan memberikan konfirmasi login, dan Admin akan diarahkan masuk pada halaman utama. Pada proses ini maka Admin akan melakukan kegiatan seperti memasukan 
data-data kehadiran (Absensi), mencari data absensi dan melakukan proses prediksi (forecasting). Dan sistem akan menampilkan input data-data serta forecasting yang dilakukan oleh Admin. DFD Level 0 ditunjukkan pada Gambar 3

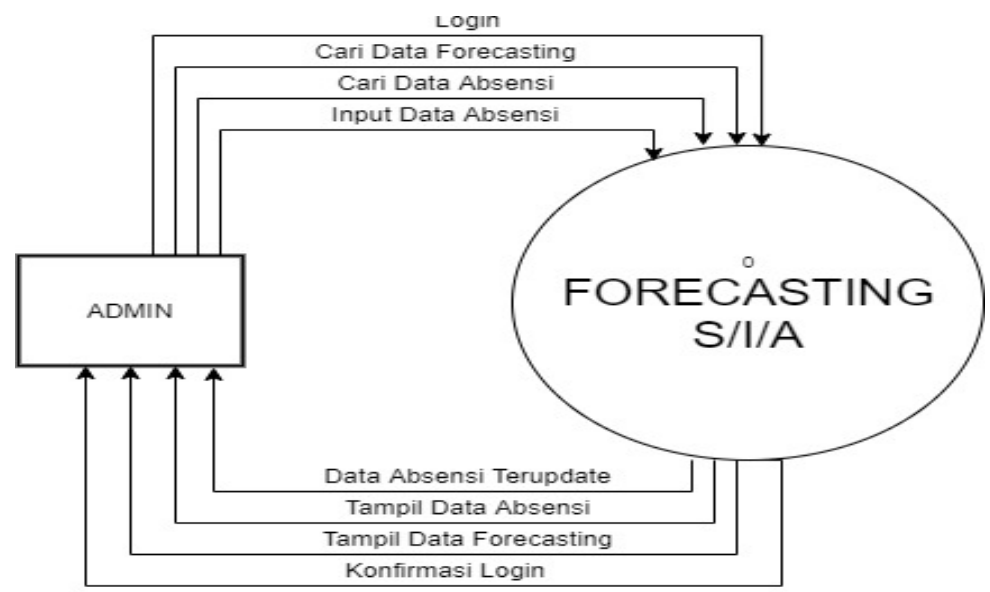

Gambar 3. DFD Level 0

Dalam DFD Level 1, dijelaskan admin melakukan proses login dengan memasukan Username dan Password, jika data admin yang dimasukan bisa diterima sistem, maka admin akan diarahkan pada halaman utama yang berisi menu Input Data, Tampil Data dan Prediksi Data. Admin bisa melakukan input data absensi, pencarian data absensi dan pencarian data forecasting, jika proses berhasil maka data absensi terbaharui, tampil data absensi dan tampil hasil forecasting. DFD Level 1 ditunjukan pada Gambar 4.



Gambar 4. DFD Level 1

Dalam DFD level 2, dijelaskan lebih detail alur proses admin melakukan input data kelas berdasarkan data kelas yang akan menampilkan informasi kelas dan input data absensi berdasarkan data absensi menampilkan informasi tentang kehadiran. DFD Level 2 ditunjukan pada Gambar 5. 


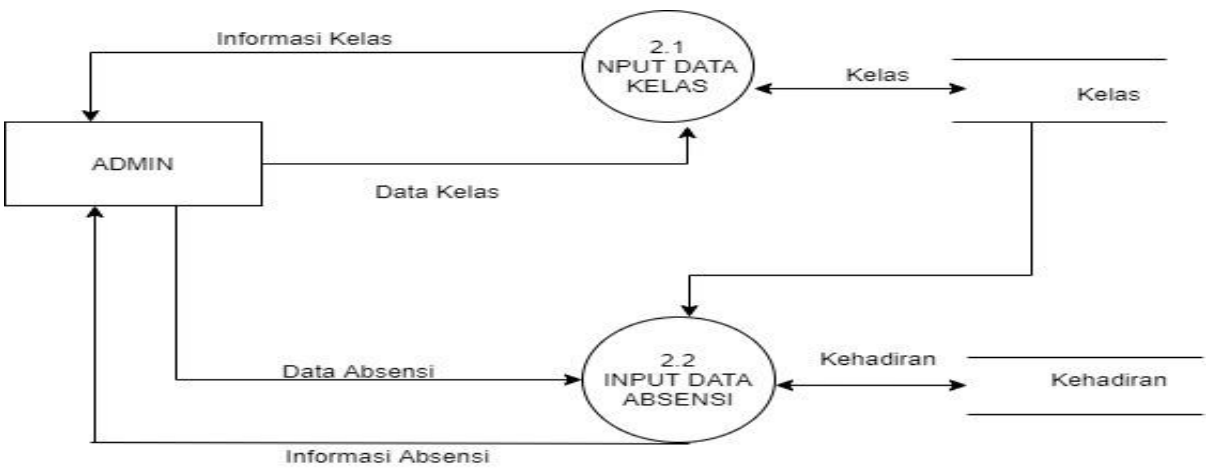

Gambar 5. DFD Level 2

\section{d. Flowchart Sistem}

Setelah Entity Relationship Diagram dan Data Flow Diagram beserta rancangan antar muka dibuat, selanjutnya adalah membuat flowchart untuk mengetahui proses alur dari sistem aplikasi yang dipadukan dengan data yang telah ada sehingga dapat berinteraksi antara data dengan alur programnya.

Penggunaan Aplikasi Forecasting Kehadiran Siswa ini dimulai dengan Admin melakukan login pada aplikasi yaitu dengan memasukan User Name dan Password, jika data yang dimasukan benar maka akan berhasil masuk pada halaman utama, jika User Name dan Password yang dimasukan tidak sesuai maka akan muncul peringatan dari sistem. Proses Login ditunjukkan pada Gambar 6. Flowchart Login.

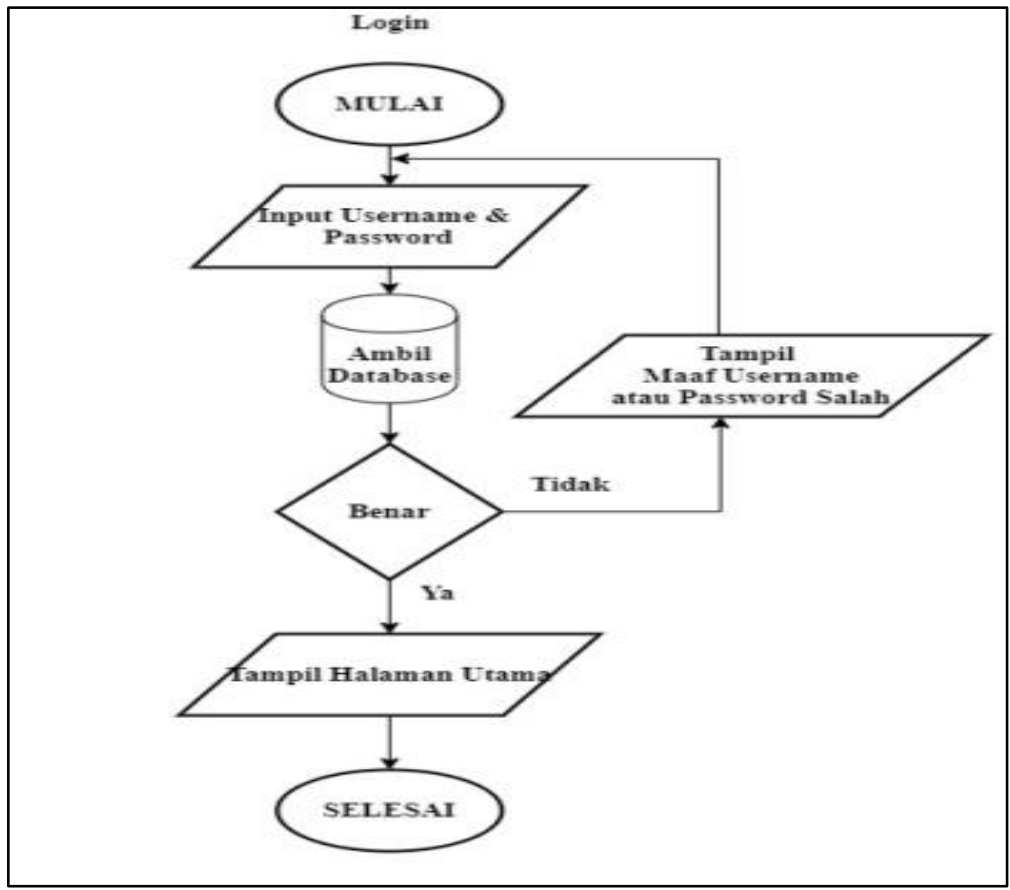

Gambar 6. Flowchart Login

Input Data menunjukkan proses data-data yang harus dimasukankan oleh admin. Data-data yang harus dimasukkan antara lain: Data Kelas, Bulan, Semester, Tahun, Keterangan (Sakit, Izin, Alpha) dan jumlah ketidak hadiran. Jika proses memasukkan data berhasil maka akan disimpan dalam database. Proses Input Data ditunjukkan pada Gambar 7. Flowchart Input Data. 


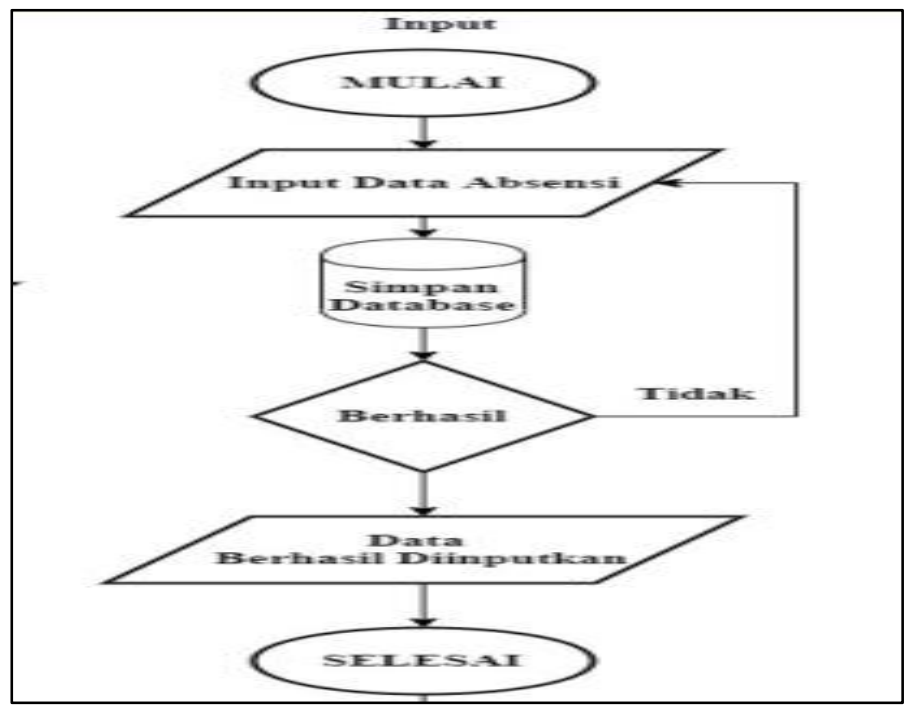

Gambar 7. Flowchart Input Data

Pada Tampil Data akan menampilkan hasil perhitungan (forecasting) berdasarkan data-data yang sudah dimasukan pada Input Data.Ditunjukan pada Gambar 8. Flowchart Tampil Data.

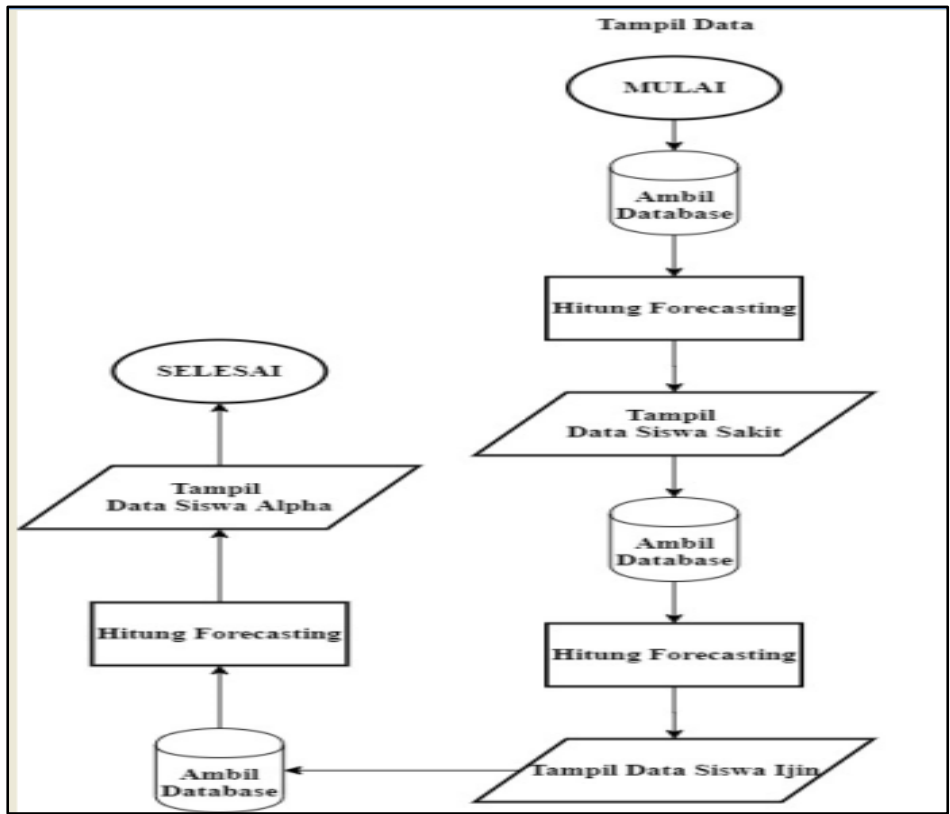

Gambar 8. Flowchart Tampil Data

Prediksi Data menampilkan alur proses prediksi dimana proses dimulai dengan memilih bulan dan kriteria kehadiran (S/I/A) yang akan diprediksi, jika proses berhasil maka ssstem akan menampilkan hasil prediksi. Ditunjukkan pada Gambar 9. Flowchart Prediksi Data. 


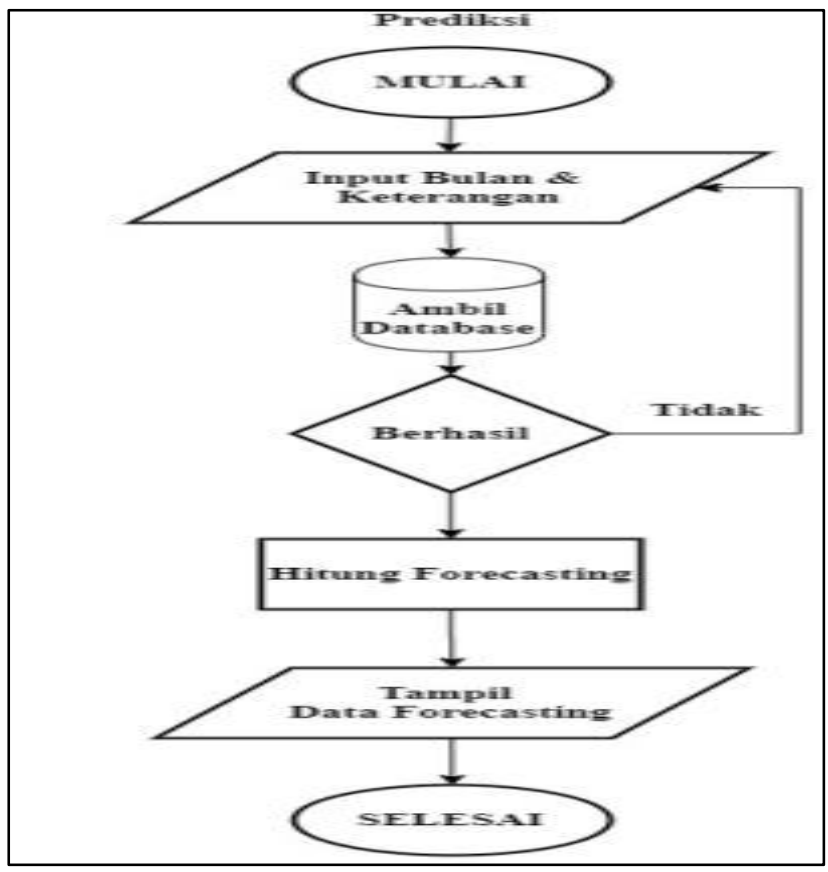

Gambar 9. Flowchart Prediksi Data

\subsection{Implementasi}

Implementasi adalah tahap penerapan sekaligus pengujian aplikasi yang telah dibangun, untuk melangkah ke implementasi yang harus didukung dengan tools dan fasilitas yang tepat. Berikut merupakan tampilan antar muka aplikasi forecasting kehadiran siswa di SMP 2 Jekulo..

\section{a. Halaman Login}

Sistem dibangun hanya mempunyai fitur login untuk admin. Admin bertugas sebagai pemegang penuh dan bertanggung jawab terhadap data yang ada didalam sistem. Login pada level ini dapat melakukan pengelolaan data, menambah, mengedit, dan menghapus data ketidak hadiran siswa dengan kategori sakit, izin dan alpha Admin adalah guru Bimbingan Konselingr. Halaman login merupakan halaman yang digunakan untuk admin login ke sistem. Jika username dan password di ketik dengan benar maka admin akan masuk ke dalam sistem. Halaman Login ditunjukkan pada Gambar 10 .

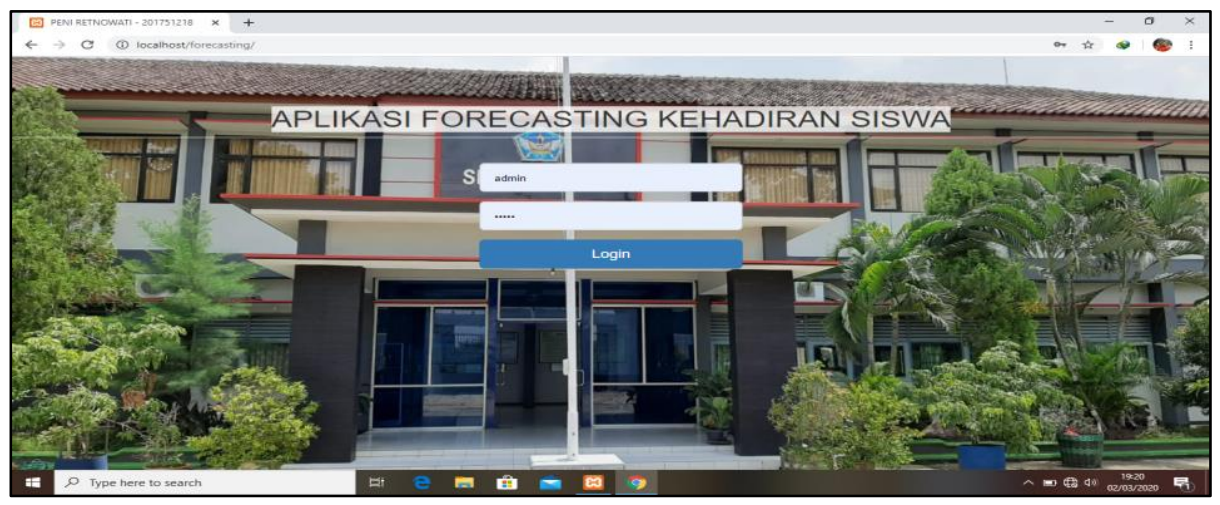

\section{b. Halaman Utama}

Gambar 10. Halaman Login 
Setelah mengisi username dan password agar bisa login, admin akan diarahkan pada halaman utama, terdapat menu pilihan yang bisa diakses yaitu : input data, tampil data, prediksi data dan logout. Input Data akan mengarahkan pada jenis data yang akan dimasukkan. Tampil Data akan menampilkan hasil masukan data, sedang Prediksi Data akan memproses dan menampilkan hasil prediksi. Halaman utama ditunjukkan pada gambar 11 .

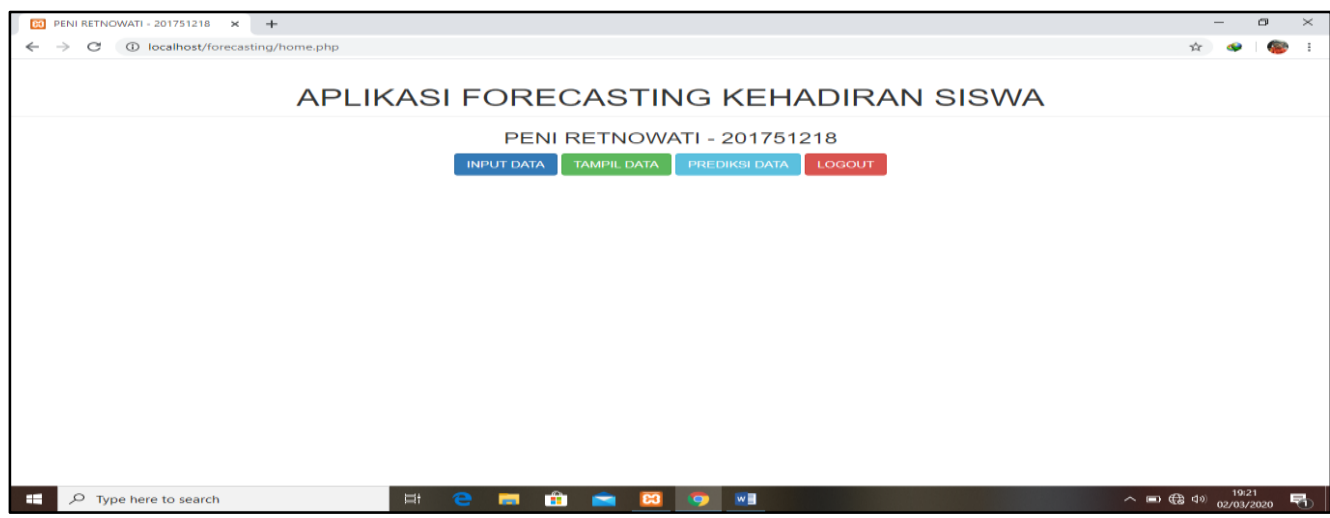

\section{Gambar 11. Halaman Utama}

\section{c. Halaman Input Data}

Pada halaman input data, admin akan diarahkan untuk mengisi form berupa data-data yang diperlukan untuk melakukan perhitungan prediksi kehadiran. Adapaun data yang diisi antara lain : kelas, bulan, semester, tahun, keterangan (sakit, izin, alpha) dan jumlah. Data-data yang dimasukan adalah dari data kehadiran siswa yang dapat ditambah, diubah, maupun dihapus oleh admin. Halaman input data ditunjukkan pada gambar 12.

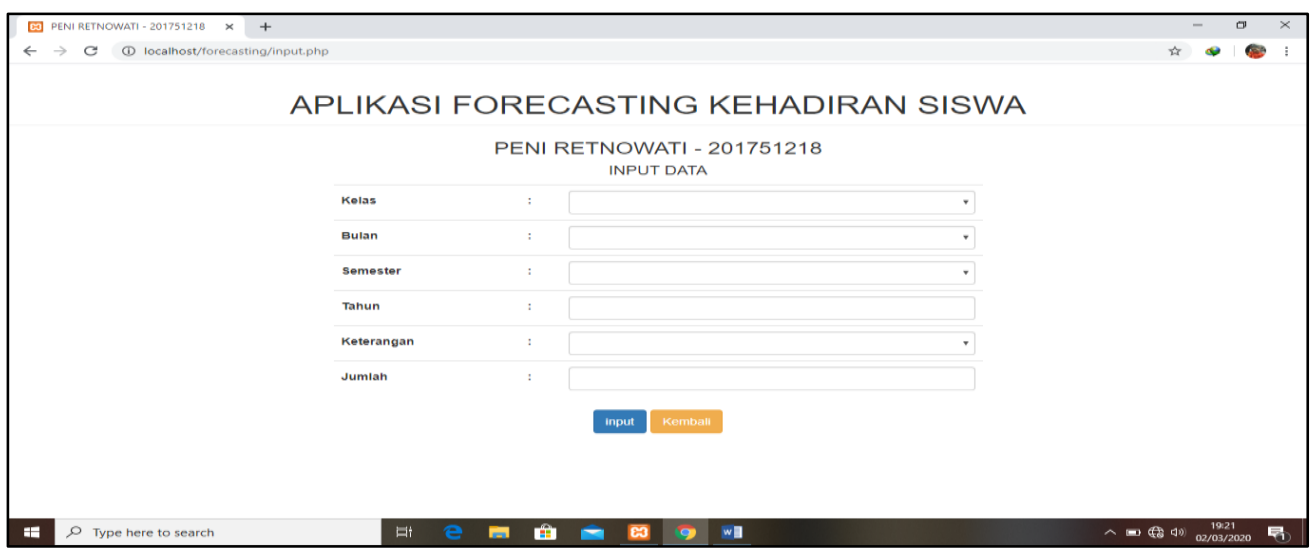

\section{Gambar 12. Halaman Input Data}

\section{d. Halaman Tampil Data}

Setelah mengisi lengkap data yang diperlukan pada halaman input data, maka admin dapat menampilkan data yang dimasukkan pada halaman tampil data. Pada halaman Tampil Data, admin juga dapat melakukan perubahan pada data yang sudah dimasukan dengan melakukan aksi hapus data. Halaman tampil data ditunjukkan pada gambar 13. 


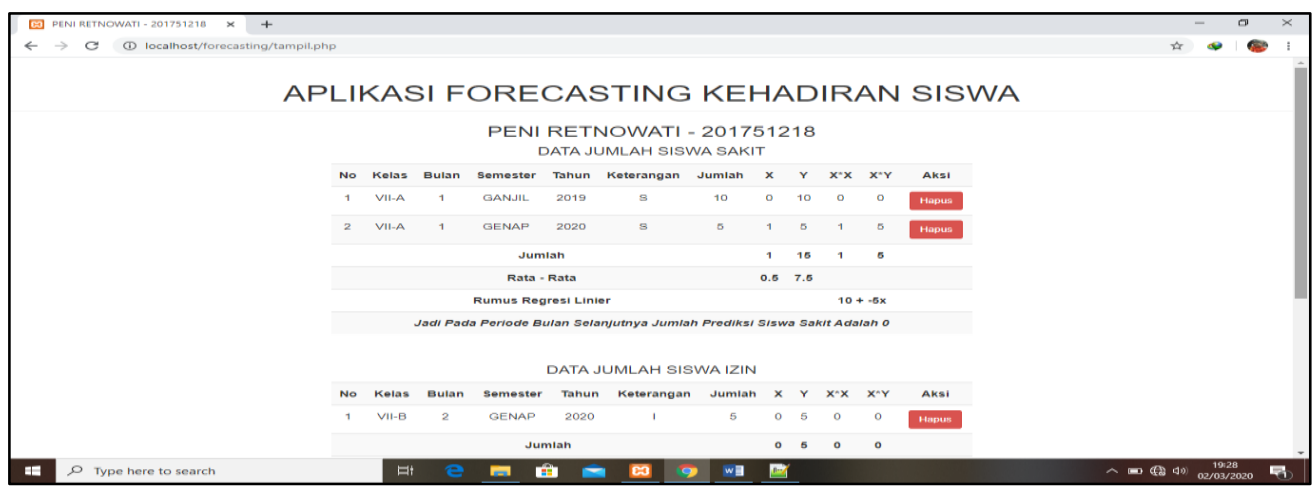

Gambar 13. Halaman Tampil Data

\section{e. Halaman Prediksi Data dan Hasil Prediksi Data}

Untuk bisa melakukan prediksi pada halaman prediksi data, maka admin harus memasukkan bulan dan keterangan seperti sakit, izin atau alpha yang akan diprediksi. Halaman prediksi data ditunjukkan pada gambar 14

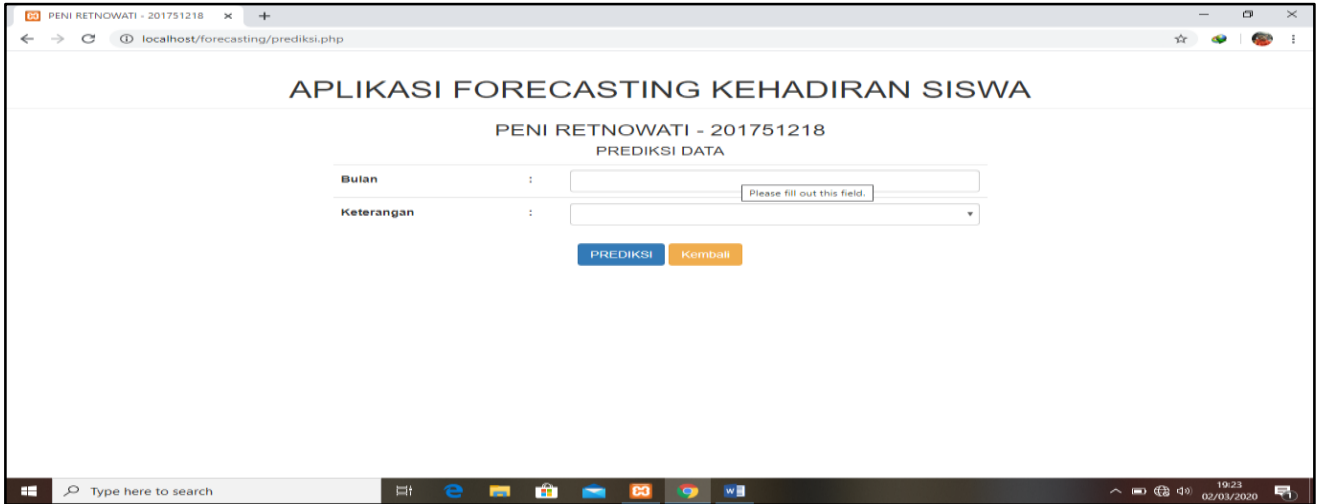

\section{Gambar 14. Halaman Prediksi Data}

Dan pada halaman hasil prediksi data menampilkan hasil prediksi kehadiran siswa berdasarkan data yang dimasukan saat akan melakukan prediksi yaitu bulan dan keterangan berupa sakit, izin atau alpha. Halaman hasil prediksi data ditunjukkan pada gambar 15

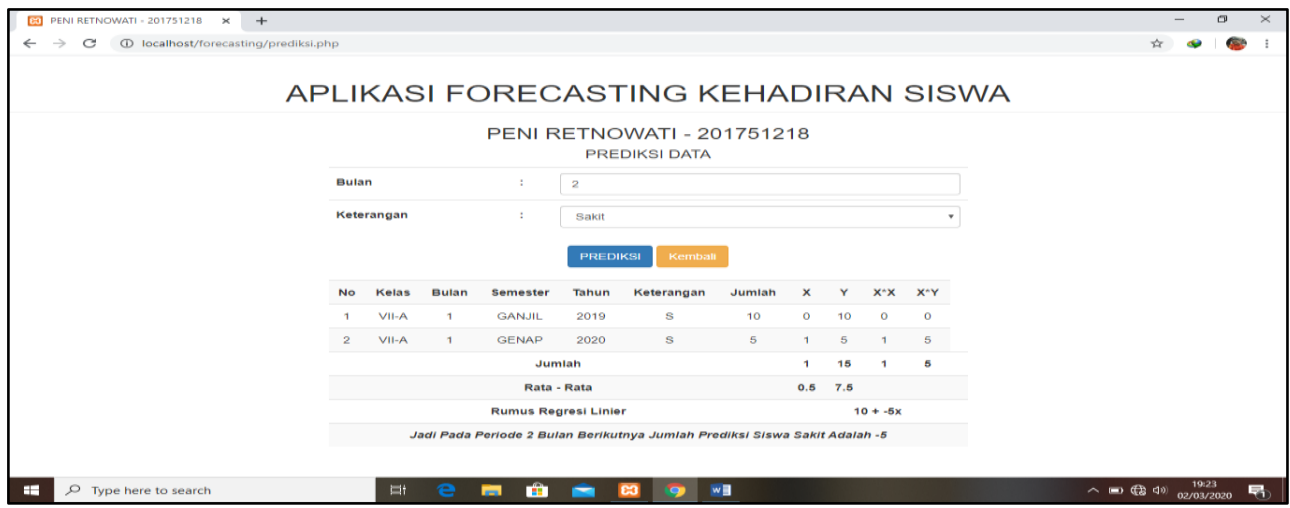




\section{f. Pengujian}

\section{Gambar 15. Halaman Hasil Prediksi Data}

Pengujian yang dilakukan pada Aplikasi Forecasting Kehadiran Siswa di SMP 2 Jekulo ini adalah pengujian BlackBox. Pengujian dilakukan untuk mengetahui apakah rumus yang digunakan dalam aplikasi sudah sesuai atau belum. Daftar pengujian dapat dilihat pada Gambar 16 adalah perhitungan forecasting menggunakan Microsoft Excel dan Gambar 17 perhitungan menggunakan aplikasi, bertujuan memprediksi jumlah siswa sakit pada bulan selanjutnya sebagai berikut:

\begin{tabular}{|c|c|c|c|c|c|c|c|}
\hline 4 & A & B & C & D & $E$ & $\mathrm{~F}$ & G \\
\hline 1 & \multicolumn{7}{|c|}{ DATA SISWA SAKIT SEMESTER GANJIL TH.2019 } \\
\hline 2 & Nomor & Bulan & Jumlah & $\mathbf{x}$ & $\mathbf{y}$ & $\mathbf{x x}$ & xy \\
\hline 3 & 1 & Bulan Juli & 73 & 0 & 73 & 0 & 0 \\
\hline 4 & 2 & Bulan Agustus & 233 & 1 & 233 & 1 & 233 \\
\hline 5 & 3 & Bulan September & 130 & 2 & 130 & 4 & 260 \\
\hline 6 & 4 & Bulan Oktober & 229 & 3 & 229 & 9 & 687 \\
\hline 7 & 5 & Bulan November & 167 & 4 & 167 & 16 & 668 \\
\hline 8 & 6 & Bulan Desember & 23 & 5 & 23 & 25 & 115 \\
\hline \multicolumn{8}{|l|}{9} \\
\hline 10 & Jumlah & & & 15 & 855 & 55 & 1963 \\
\hline 11 & Rata-Rata & & & 2,5 & 142,5 & & \\
\hline \multicolumn{8}{|l|}{12} \\
\hline 13 & B1 & $=(\mathrm{G} 10-((\mathrm{D} 10 * \mathrm{E} 10) / \mathrm{A} 8)) / \mathrm{F} 10-((\mathrm{D} 10 * \mathrm{D} 10) / \mathrm{A} 8))$ & & & & $-9,9$ & 428571 \\
\hline 14 & B0 & $=\mathrm{E} 11-\left(\mathrm{C} 13^{*} \mathrm{D} 11\right)$ & & & & 167 & 285714 \\
\hline 15 & $\mathbf{Y}$ & $=\mathrm{C} 14 \& "+" \& \mathrm{C} 13 \& " \mathrm{X} "$ & 167 & 1285714 & $571+-9$, & 7142857 & $12857 \mathrm{X}$ \\
\hline 16 & Prediksi & $=\mathrm{C} 14+(\mathrm{C} 13 * \mathrm{C} 17)$ & & & & & 107,6 \\
\hline 17 & $\mathbf{x}$ & 1 Bulan selanjutnya & & & & & 6 \\
\hline
\end{tabular}

Gambar 16. Perhitungan Prediksi Siswa Sakit (Microsoft Excel)

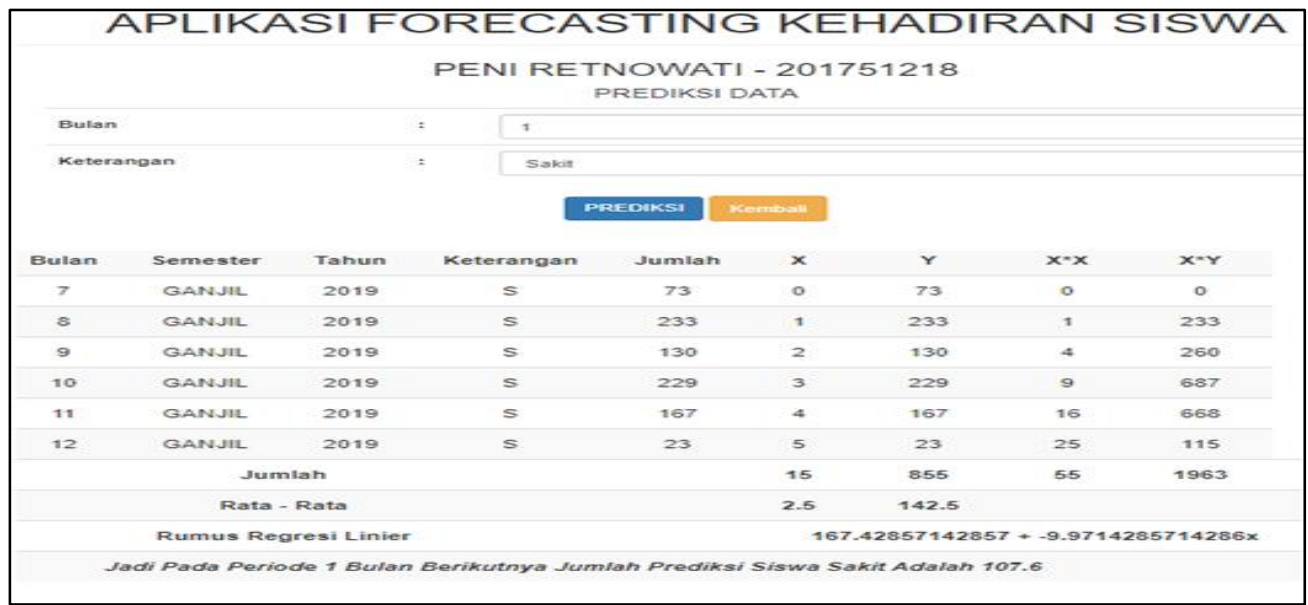

Gambar 17. Perhitungan Prediksi Siswa Sakit (Aplikasi)

Dari Daftar pengujian pada Gambar 16 yaitu perhitungan forecasting menggunakan Microsoft Excel dan Gambar 17 perhitungan menggunakan aplikasi, dengan tujuan memprediksi jumlah siswa sakit pada bulan selanjutnya diperoleh hasil perhitungan yang sama.

Berikutnya pengujian prediksi jumlah siswa izin pada satu bulan berikutnya dapat dilihat pada Gambar 18 yaitu perhitungan forecasting menggunakan Microsoft Excel dan Gambar 19 perhitungan menggunakan aplikasi, dan diperoleh hasil perhitungan yang sama. 


\begin{tabular}{|c|c|c|c|c|c|c|c|}
\hline 4 & A & B & $\mathrm{C}$ & D & $\mathrm{E}$ & $\mathrm{F}$ & G \\
\hline 1 & \multicolumn{7}{|c|}{ DATA SISWA IZIN SEMIESTER GANJIL TH.2019 } \\
\hline 2 & Nomer & Bulan & Jumlah & $\mathrm{x}$ & $\mathrm{y}$ & $\mathrm{xx}$ & $\mathrm{xy}$ \\
\hline 3 & 1 & Bulan Juli & 40 & 0 & 40 & 0 & 0 \\
\hline 4 & 2 & Bulan Agustus & 170 & 1 & 170 & 1 & 170 \\
\hline 5 & 3 & Bulan September & 37 & 2 & 37 & 4 & 74 \\
\hline 6 & 4 & Bulan Oktober & 74 & 3 & 74 & 9 & 222 \\
\hline 7 & 5 & Bulan November & 39 & 4 & 39 & 16 & 156 \\
\hline 8 & 6 & Bulan Desember & 7 & 5 & 7 & 25 & 35 \\
\hline \multicolumn{8}{|l|}{9} \\
\hline 10 & Jumlah & & & 15 & 367 & 55 & 657 \\
\hline 11 & \multicolumn{2}{|l|}{ Rata-Rata } & & 2,5 & 61,1667 & & \\
\hline \multicolumn{8}{|c|}{12} \\
\hline 13 & B1 & $=(\mathrm{G} 10-((\mathrm{D} 10 * \mathrm{E} 10) / \mathrm{As})) / \mathrm{F} 10-((\mathrm{D} 10 * \mathrm{D} 10) / \mathrm{As}))$ & \multicolumn{5}{|c|}{$-14,88571429$} \\
\hline 14 & B0 & $=$ E11 $-(C 13 *$ D11 $)$ & \multicolumn{5}{|c|}{98,38095238} \\
\hline 15 & $\mathbf{Y}$ & $=C 14 \& "+" \& C 13 \& " X "$ & \multicolumn{5}{|c|}{$98,3809523809524+-14,8857142857143 X$} \\
\hline 16 & Prediksi & $=\mathrm{Cl} 14+\left(\mathrm{Cl13}^{*} \mathrm{Cl}\right)$ & \multicolumn{5}{|c|}{9,066666667} \\
\hline 17 & $\mathbf{x}$ & 1 Bulan selanjutnya & & & & & 6 \\
\hline
\end{tabular}

\section{Gambar 18. Perhitungan Prediksi Siswa Izin (Microsoft Excel)}

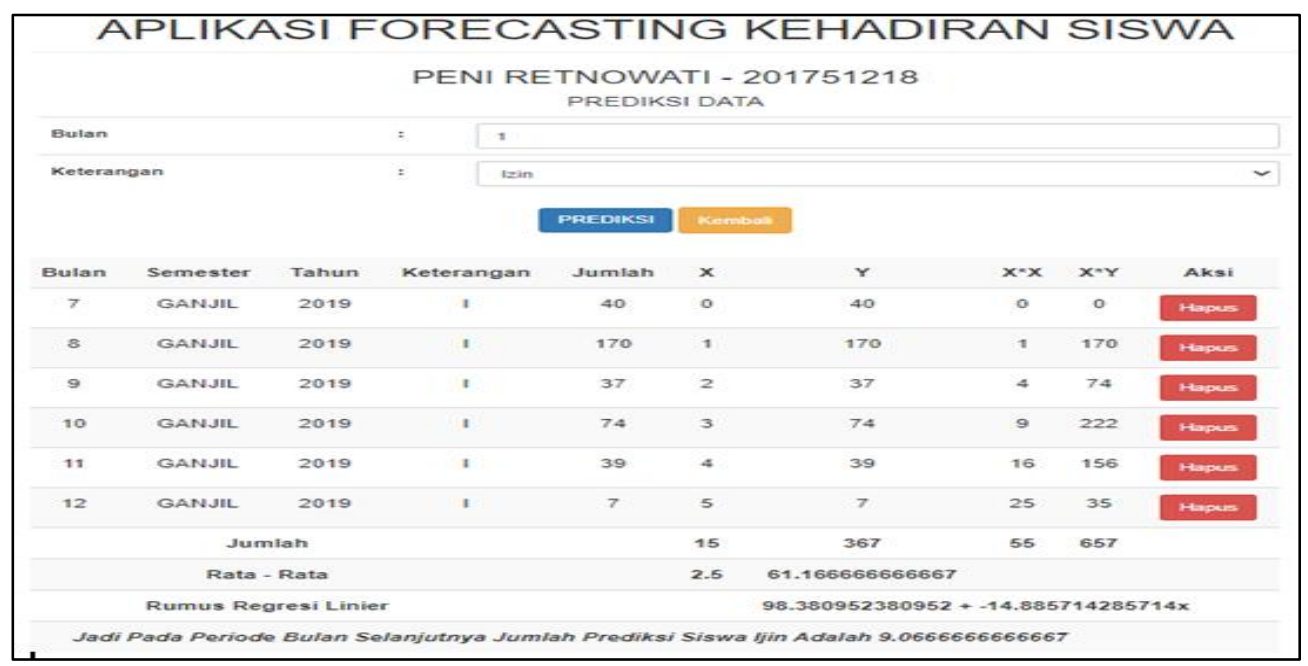

Gambar 19. Perhitungan Prediksi Siswa Izin (Aplikasi)

Demikian pula pada pengujian prediksi jumlah siswa alpha pada satu bulan berikutnya dapat dilihat pada Gambar 20 yaitu perhitungan forecasting menggunakan Microsoft Excel dan Gambar 21 perhitungan menggunakan aplikasi, dan diperoleh hasil perhitungan yang sama pula. 


\begin{tabular}{|c|c|c|c|c|c|c|c|}
\hline 4 & A & B & $\mathrm{C}$ & D & $E$ & $\mathrm{~F}$ & G \\
\hline 1 & \multicolumn{7}{|c|}{ DATA SISWA ALPHA SEMESTER GANJIL TH.2019 } \\
\hline 2 & Nomer & Bulan & Jumlah & $\mathbf{x}$ & $\mathbf{y}$ & $\mathbf{x x}$ & xy \\
\hline 3 & 1 & Bulan Juli & 13 & 0 & 13 & 0 & 0 \\
\hline 4 & 2 & Bulan Agustus & 57 & 1 & 57 & 1 & 57 \\
\hline 5 & 3 & Bulan September & 32 & 2 & 32 & 4 & 64 \\
\hline 6 & 4 & Bulan Oktober & 41 & 3 & 41 & 9 & 123 \\
\hline 7 & 5 & Bulan November & 44 & 4 & 44 & 16 & 176 \\
\hline 8 & 6 & Bulan Desember & 3 & 5 & 3 & 25 & 15 \\
\hline \multicolumn{8}{|l|}{9} \\
\hline 10 & Jumlah & & & 15 & 190 & 55 & 435 \\
\hline 11 & \multicolumn{2}{|l|}{ Rata-Rata } & & 2,5 & 31,6667 & & \\
\hline 12 & & & & & & & \\
\hline 13 & B1 & $=(\mathrm{G} 10-((\mathrm{D} 10 * \mathrm{E} 10) / \mathrm{A} 8)) / \mathrm{F} 10-((\mathrm{D} 10 * \mathrm{D} 10) / \mathrm{AS}))$ & \multicolumn{5}{|c|}{$-2,285714286$} \\
\hline 14 & B0 & $=\mathrm{E} 11-(\mathrm{C} 13 * \mathrm{D} 11)$ & \multicolumn{5}{|c|}{37,38095238} \\
\hline 15 & $\mathbf{Y}$ & $=\mathrm{C} 14 \& "+" \& C 13 \& " \mathrm{X} "$ & \multicolumn{5}{|c|}{$37,3809523809524+-2,28571428571429 \mathrm{X}$} \\
\hline 16 & Prediksi & $=\mathrm{Cl} 14+(\mathrm{C} 13 * \mathrm{Cl} 1)$ & \multicolumn{5}{|c|}{23,66666667} \\
\hline 17 & $\mathrm{x}$ & 1 Bulan selanjutnya & & & & & 6 \\
\hline
\end{tabular}

\section{Gambar 20. Perhitungan Prediksi Siswa Alpha (Microsoft Excel)}

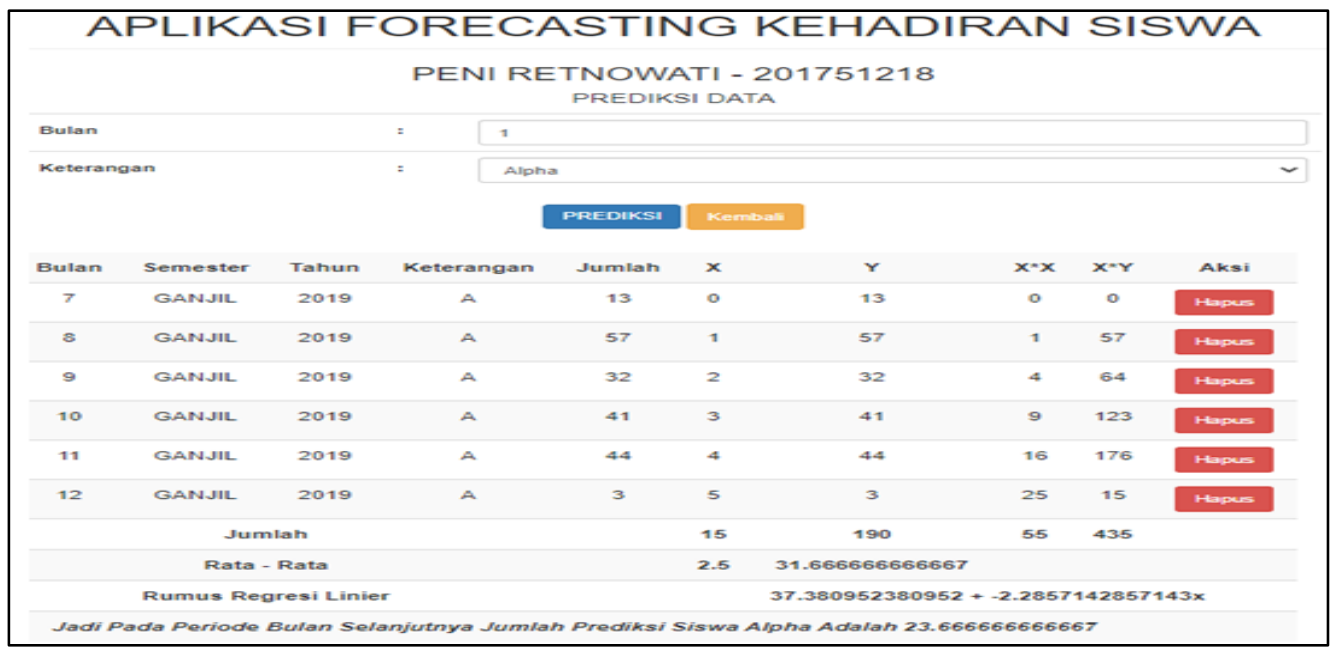

Gambar 21. Perhitungan Prediksi Siswa Alpha (Aplikasi)

\section{KESIMPULAN}

Kesimpulan yang dapat ditarik berdasarkan hasil dan pembahasan diatas tentang aplikasi forecasting kehadiran siswa di SMP 2 Jekulo adalah sebagai berikut:

a. Telah dihasilkan Aplikasi Forecasting Kehadiran Siswa berbasis teknologi informasi (web) yang dapat digunakan untuk melakukan prediksi kehadiran siswa berdasarkan data pada periode sebelumnya selama waktu tertentu.

b. Aplikasi Forecasting Kehadiran Siswa berbasis teknologi informasi (web) memberikan manfaat yaitu prediksi ketidakhadiran siswa berdasarkan keterangan sakit (S), izin(I) dan alpha (A) dapat dilakukan dengan cepat dan mudah sehingga Guru BK mampu merancang langkah-langkah secara efektif dalam meningkatkan kedisiplinan siswa

Dalam pembuatan aplikasi forecasting kehadiran siswa di SMP 2 Jekulo masih ada banyak hal yang dapat dikembangkan, seperti:

a. Fitur dan tampilan yang tersedia masih sangat terbatas dan sederhana harapan kedepannya fitur dan tampilan bisa diperbaharui dengan desain tampilan yang lebih menarik dan fitur yang lebih lengkap dan memadai. 
b. Aplikasi masih terbatas pada rekap data hadir dan tidak hadir dengan keterangan sakit, izin dan alpha, harapannya aplikasi forecasting kehadiran siswa bisa terintegrasi dengan sistem absensi (presensi) disekolah

\section{DAFTAR PUSTAKA}

[1] Suryono dan Hariyanto, (2014). Belajar dan Pengajaran: Teori dan Konsep Dasar. Bandung: PT Remaja Rosdakarya. Sukamto, \& Shalahuddin. (2013). Analisa dan Desain Sistem Informasi. Yogyakarta: Andi Offset. (1)

[2] Zain, Mirrah, Ni Ketut Dewi Ari Jayanti, Yohanes Priyo Atmojo. 2013. "Implementasi Forecasting Pada Perancangan Sistem Pembukaan Kelas di STIKOM Bali dengan Menggunakan Metode Regresi Linear", Eksplorasi Informatika. Vol. 3. No. 1, pp 17-28. (2)

[3] Khotimah, Tutik, Ratih Nindyasari. 2017. "Forecasting Dengan Metode Regresi Linier Pada Sistem Penunjang Keputusan Untuk Memprediksi Jumlah Penjualan Batik (Studi Kasus Kub Sarwo Endah Batik Tulis Lasem)", Jurnal Mantik Penusa, Vol 1 No 1, pp 72-75 (3)

[4] Iik, Ade .2017. "Analisis Penerapan Forecasting Dalam Penentuan Anggaran Penjualan Dan Implikasinya Terhadap Peningkatan Penjualan Perusahaan”. Jurnal Ekonologi, Vol 4. No 1. (4)

[5] Amiruddin, Rezqiwati Ishak, 2018. "Prediksi Jumlah Mahasiswa Registrasi Per Semester Menggunakan Linier Regresi Pada Universitas Ichsan Gorontalo “. ILKOM Jurnal Ilmiah. Vol 10. No 2, pp 136-143. (5)

[6] Ayuni, Ghebyla Najlai, Devi Fitriana. 2019 "Penerapan Metode Regresi Linear Untuk Prediksi Penjualan Properti pada PT XYZ”. Jurnal Telematika, Vol.14. No. 2, pp 79-85. (6)

[7] Imron, Ali Tahun: 1994. Manajemen Peserta Didik Jilid 1. Malang: Proyek OPF IKIP Malang (7)

[8] Makridakis. 1999. Metode dan aplikasi peramalan. Edisi 2. Jakarta: Binarupa Aksara. (8)

[9] Mulyani, Dr. Sri. (2016). Metode Analisis dan Perancangan. Sistem. Bandung: Abdi SisteMatika. [9]

[10] Sukamto, \& Shalahuddin. (2013). Analisa dan Desain Sistem Informasi. Yogyakarta: Andi Offset. 